\title{
Editorial
}

\section{Welcome to the International Journal of Neonatal Screening}

\section{Ralph Fingerhut}

Swiss Newborn Screening Laboratory, Children's Research Center, University Children's Hospital, Steinwiesstr. 75, CH-8032 Zurich, Switzerland; E-Mail: ralph.fingerhut@kispi.uzh.ch; Tel.: +41-44-266-7732; Fax: +41-44-266-8110.

Received: 15 December 2014 / Accepted: 18 December 2014 / Published: 31 December 2014

"Third time is a charm", with this adage I would like to introduce the International Journal of Neonatal Screening (IJNS). Why three times? Well, this is the third time that the International Society for Neonatal Screening (ISNS) has launched its official journal. The first one, Screening, began in 1992, one year after the constitution of ISNS. In 1996, after Vol. 4 No.4 was printed, the publication of Screening had to be stopped. It was too expensive for the small number of members, and there were not enough institutional subscriptions (if any at all), that could compensate for the deficit. Since Screening was never indexed, the large number of high quality articles dealing with newborn screening aspects that were published in the four volumes have stayed invisible for most of the scientific community. In 1996 ISNS and the Journal of Medical Screening (JMS) agreed to have JMS as the society's journal, but unfortunately over the years only a few manuscripts from ISNS members were submitted to JMS. Despite the efforts of ISNS council members, the situation did not change and JMS and the ISNS council decided to discontinue the collaboration from 2002. Since then, ISNS has had no official journal, and the ISNS newsletter has been until now the only forum for information exchange between members. But now, after 13 years of abstinence, ISNS makes a new attempt - the third one.

With all the established journals and a cavalcade of new open access journals, does the market really need another one? Yes, it does! And I will give you three reasons why: 1) IJNS will be the definitive platform where newborn screening labs can exchange their experience with tests and test kits (good and bad), improvements and adaptations. 2) IJNS will be the interdisciplinary platform for all specialists around newborn screening (NBS) - technicians, scientist, physicians, clinical chemists, metabolic specialists, paediatric endocrinologists, paediatric pneumologists, paediatric immunologists, public health specialists and others. 3) IJNS will become the number one journal in the field of newborn screening. "Third time is a charm."

I know that my vision of the development of IJNS is very enthusiastic, but since the idea took shape in my head approximately a year ago - that ISNS and the screening community needs a platform to exchange and publish especially these "technical notes" that are so helpful for NBS labs, but so hard to 
publish - the whole project has undergone an exponential development. At the beginning, some of my fellow council members might have asked themselves, "is he still following this journal idea?", but I think that was just a normal process, to check the possibilities, and then decide which way to go.

Then, while checking the possibilities of open access publishing, I stumbled across MDPI. I can't remember how and why, but we had a first appointment and I was sure this was the start of a long and fruitful cooperation. It took some time to discuss the details of the publishing agreement, before we could inform the ISNS members at the general membership meeting end of October. But from then on it has sped up like a rocket. And while I am sitting in front of my computer writing this editorial two weeks before Christmas, we are at the same time creating and planning the journal logo, setting-up the editorial board, and attracting articles for the first issue. But, after speeding up like a rocket, I am convinced IJNS will have an impact from the first issue onwards.

This leads me from impact to impact factor, and the problem that every new journal faces. We have been able to attract many top experts in the field to contribute to the first issue of the journal, and I really want to thank all of them for this, especially because we did not give them much time. The difficult task for the editorial board, ISNS, and MDPI will now be to attract other scientists from all over the world to submit their manuscripts and research from the wide field of NBS to IJNS. So I would try to convince every potential author to think about what he or she wants for his or her research and his or her article: do you want impact or do you just want an impact factor? Choosing your journal to publish by impact factor does not necessarily warrant that your article has impact, meaning that it will be read and cited. However if you choose to publish your research in the NBS field in IJNS, impact will be guaranteed, because it will be read by at least all 385 ISNS members.

Finally, I want to thank the ISNS council for the support to get IJNS started, my managing editor, Delia Costache, and the staff at MDPI who made IJNS happen, and you all, ISNS members, colleagues, scientists, and readers of IJNS, who will submit your high quality research to IJNS. I am sure if we think about impact rather than impact factor, then, together we will make IJNS a success.

C 2014 by the authors; licensee MDPI, Basel, Switzerland. This article is an open access article distributed under the terms and conditions of the Creative Commons Attribution license (http://creativecommons.org/licenses/by/4.0/). 